\title{
Erratum to: Talar Fractures: The Injury, the Management, and the Aftermath
}

Justin J. Fleming, Kwasi Y. Kwaadu, and Michael W. Downey

\section{Erratum to:}

Chapter 18 in: M.S. Lee, J.P. Grossman (eds.), Complications in Foot and Ankle Surgery, DOI 10.1007/978-3-319-53686-6_18

The original version of this book was published without Michael W. Downey listed among the chapter authors in Chapter 18. It has been corrected and updated as:

Justin J. Fleming, Kwasi Y. Kwaadu, and Michael W. Downey 